\title{
High proportion of mutant K-ras gene in pancreatic juice of patients with pancreatic cystic lesions
}

K Tateishi, M Tada, M Yamagata, H Isayama, Y Komatsu, T Kawabe, Y Shiratori, M Omata

\begin{abstract}
BackgroundlAims-It was recently reported that the quantitative analysis of mutant $\mathrm{K}$-ras gene in pancreatic juice could be useful for the diagnosis of pancreatic cancer. This methodology was applied to patients with pancreatic cystic lesions.

Methods-DNA was extracted from pancreatic juice collected at the time of endoscopy with injection of secretin. The ratio of the K-ras mutant allele to the wild-type allele was measured by two methods to detect and semiquantify mutant K-ras gene: polymerase chain reaction/preferential homoduplex formation assay and enriched polymerase chain reaction/enzyme linked mini-sequence assay.

Results-A high frequency of K-ras mutation was detected (more than $2 \%$ of all K-ras genes) in six of 14 patients (43\%) with pancreatic cysts. This frequency was similar to those detected in patients with pancreatic adenocarcinoma and in intraductal papillary neoplasms of the pancreas. In contrast, the frequency of mutation was low (less than 2\%) in patients without either pancreatic cysts or pancreatic neoplasms.

Conclusions-K-ras gene mutation may be derived from duct cells in the pancreas with a high potential for tumorigenesis. Therefore careful follow up of patients with a pancreatic cyst is recommended if they are found to have a high level of the mutant gene in the pancreatic juice. (Gut 1999;45:737-740)
\end{abstract}

Keywords: pancreas; cyst; K-ras; pancreatic adenocarcinoma; quantitative analysis

We and others have previously reported the presence of K-ras mutations in pancreatic secretions as a molecular marker for pancreatic carcinoma because this cancer is known for their high incidence. ${ }^{1-4}$ The main problem in these studies was the occasional presence of these mutations in normal or inflammatory pancreatic duct cells..$^{5-8}$ Thus we decided to quantify cells carrying mutations in order to solve the problem of duct cells derived from non-malignant tissue, and we showed that quantitative analysis could explain the difference between pancreatic neoplasms and non-neoplasms. ${ }^{9}$
Unlike qualitative detection of ras gene mutation, quantification of the mutant in pancreatic juice proved to be helpful for differential diagnosis of pancreatic tumours, as there was a higher amount of K-ras mutant associated with pancreatic carcinoma than in non-neoplastic cases. In a previous study, however, we found two cases that were exceptions: a high level of the mutant gene (more than $1 \%$ ) was found in the pancreatic juice from two patients without pancreatic carcinoma or chronic pancreatitis. ${ }^{9}$ When we carefully re-examined the clinical features of these two cases, we noticed that the patients had cystic lesions in the pancreas that had no apparent relation to pancreatic neoplasms or chronic pancreatitis.

The most common cystic lesions of the pancreas are pseudocysts, accounting for more than half of pancreatic cystic lesions. ${ }^{10}{ }^{11}$ The other cysts are neoplastic ones such as mucinous and serous cystadeno(carcino)ma, solitary or multiple retention cysts, and congenital cysts. ${ }^{11}$ Pancreatic cysts have been reported to co-exist in the pancreas of patients with carcinoma in situ, although the nature of the cysts is not clear. ${ }^{12} 13$

Therefore, in this study, we semiquantitatively analysed the mutant ras gene in pancreatic juice from patients with cystic lesions in the pancreas without pancreatic neoplasms. Two useful assay kits, enriched polymerase chain reaction (PCR)/enzyme linked mini-sequence assay (ELMA) and PCR/preferential homoduplex formation assay (PHFA), were used.

\section{Patients and methods}

PATIENTS

A total of 76 patients undergoing endoscopic retrograde cholangiopancreatography (ERCP) at Tokyo University Hospital were selected for quantitative analysis of ras gene mutation in the pancreatic juice. Of these, 14 patients with cystic lesions in the pancreas were analysed (table 1). These patients consisted of eight men and six women; their age ranged from 52 to 80 (mean 65). Pseudocysts or pancreatic cysts associated with pancreatic carcinoma were excluded. These patients had no history of pancreatitis, and the character of the pancreatic cyst was as follows: no obvious pancreatic neoplasms in the pancreas, no papillary structure

Abbreviations used in this paper: ERCP, endoscopic retrograde cholangiopancreatography; PHFA, preferential homoduplex formation assay; ELMA, enzyme linked mini-sequence assay; IPN, intraductal papillary neoplasms of the pancreas. 
Table 1 Characteristics of patients with pancreatic cystic lesions

\begin{tabular}{llllll}
\hline Patient & Sex & $\begin{array}{l}\text { Age } \\
(y)\end{array}$ & $\begin{array}{l}\text { No of } \\
\text { cysts }\end{array}$ & $\begin{array}{l}\text { Size } \\
(\mathrm{mm})\end{array}$ & $\begin{array}{l}\text { Mutant ras } \\
\text { gene }\end{array}$ \\
\hline 1 & $\mathrm{M}$ & 58 & 2 & 16 & $(3+)$ \\
2 & $\mathrm{~F}$ & 71 & 3 & 17 & $(2+)$ \\
3 & $\mathrm{~F}$ & 80 & 1 & 15 & $(2+)$ \\
4 & $\mathrm{~F}$ & 62 & 4 & 20 & $(2+)$ \\
5 & $\mathrm{~F}$ & 63 & 2 & 17 & $(2+)$ \\
6 & $\mathrm{M}$ & 69 & 5 & 25 & $(2+)$ \\
7 & $\mathrm{~F}$ & 73 & 1 & 18 & $(1+)$ \\
8 & $\mathrm{M}$ & 61 & 2 & 10 & $(1+)$ \\
9 & $\mathrm{M}$ & 59 & 2 & 10 & $(1+)$ \\
10 & $\mathrm{M}$ & 53 & 1 & 15 & $(+-)$ \\
11 & $\mathrm{M}$ & 73 & 2 & 30 & $(-)$ \\
12 & $\mathrm{~F}$ & 62 & $>10$ & 3 & $(-)$ \\
13 & $\mathrm{M}$ & 52 & 1 & 40 & $(-)$ \\
14 & $\mathrm{M}$ & 61 & 2 & 27 & $(-)$ \\
\hline
\end{tabular}

Semiquantitative analysis of the mutant gene was scored as $(3+),(2+),(1+),(+-),(-)$ according to the percentage of mutant ras gene; $(3+),(2+),(1+),(+-)$, and $(-)$ represented more than $20 \%, 2-20 \%, 0.2-2 \%$, less than $0.2 \%$, and $0 \%$ (not detected) of the mutant respectively.

in the cyst, no tendency to grow, no dilatation of the main pancreatic duct, and normal papilla of Vater. The maximum size of the cysts ranged from 3 to $40 \mathrm{~mm}$ in diameter, with an average of $19 \mathrm{~mm}$. The number of cysts ranged from one to more than 10 and the average was two. Twenty patients with pancreatic adenocarcinoma, 15 with intraductal neoplasms of the pancreas, six with chronic pancreatitis, and 21 without either pancreatic neoplasms or pancreatic cysts were also analysed for comparison (table 2).

\section{Methods}

Pure pancreatic juice was collected from the pancreatic duct during ERCP with the injection of secretin. DNA was extracted from the pancreatic juice by the standard phenol/ chloroform method. ${ }^{14}$ We recently obtained similar results to the semiquantitative assay of mutant K-ras gene using our modified allele specific $\mathrm{PCR}^{9}$ and two other methods: (a) PCR/PHFA (Wakunaga Pharmaceutical Corporation, Hiroshima, Japan and SRL Corporation, Tokyo, Japan); (b) enriched PCR/ELMA (BML Corporation, Tokyo, Japan). ${ }^{15}$ The two assays are available as handy kits. Therefore mutant ras gene was analysed by these two methods in this study.

Briefly, PCR/PHFA is based on strand competition during hybridisation between a double labelled amplicon, which was prepared from biotin and dinitrophenyl labelled primers, and an unlabelled amplicon. ${ }^{16}$ Under a precisely controlled temperature gradient, the preferential formation of a homoduplex over a heteroduplex occurred. After annealing, the identical sequence of the double labelled and unlabelled amplicons resulted in a low popula-

Table 2 Clinical features of patients selected for quantitative analysis of ras gene mutation in pancreatic juice

\begin{tabular}{lllllll}
\hline & \multirow{2}{*}{$\begin{array}{c}\text { Total no } \\
\text { patients }\end{array}$} & Male & Female & & \multicolumn{2}{c}{ Mge (years) } \\
\cline { 6 - 7 } & 14 & 8 & 6 & 65 & $52-80$ \\
\hline Pancreatic cyst & 20 & 10 & 10 & 65 & $40-82$ \\
Pancreatic carcinoma & 15 & 8 & 7 & 65 & $40-80$ \\
Intraductal neoplasm of the pancreas & 6 & 3 & 3 & 59 & $31-70$ \\
Chronic pancreatitis & 21 & 12 & 9 & 64 & $47-91$ \\
Others & & & & & \\
\hline
\end{tabular}

tion of rehybridised double labelled double stranded DNA as the result of strand exchange between them. Even when the two differed by a single base substitution, the double labelled molecule was regenerated efficiently because of preferential homoduplex formation. The regenerated double labelled molecules were captured on a streptavidin coated microtitre plate and quantified enzymatically with a chromogenic substance. This technique has been applied to HLA typing, ${ }^{16}$ and was also introduced for the semiquantitative analysis of mutant K-ras gene.

Enriched PCR/ELMA was based on the enrichment procedure of mutant K-ras gene described previously, ${ }^{17}$ and this was followed by the incorporation of biotin labelled nucleotide specific for the mutant gene, which was then quantified enzymatically with a chromogenic substance. ${ }^{18}$ Firstly, K-ras gene was amplified by PCR using a primer containing an artificial base substitution in order to mediate a restriction enzyme site that was limited to the wild type K-ras gene. After amplification, the amplicon was digested with a specific restriction enzyme in order to cleave a fragment of wild type allele and to select a fragment of the mutant allele. Second round PCR was performed to amplify the mutant gene selectively. ${ }^{17}$ Then the amplification product was captured by the oligomer which was designed to hybridise adjacent to the mutation site and was immobilised in a microtitration well. In a one nucleotide primer elongation step catalysed by Taq polymerase, a single biotin labelled nucleotide corresponding to a specific mutation was incorporated; this disclosed the presence of the mutation. ${ }^{1920}$ Finally, the biotin labelled extended oligomer was semiquantified enzymatically with a chromogenic substance. ${ }^{18}$

The results of the semiquantitative analysis were scored as $(3+),(2+),(1+),(+-)$, and $(-)$ according to the percentage of mutant ras gene. All materials were measured by both assays. Because similar amounts of mutant gene were obtained to those previously reported, ${ }^{15}$ the amount obtained by enriched PCR/ELMA was used for the results. The scores $(3+),(2+),(1+)$, $(+-)$, and (-) represented approximately more than $20 \%, 2-20 \%, 0.2-2 \%$, less than $0.2 \%$, and $0 \%$ - that is, not detected-of the mutant respectively according to the manufacturer. All codons (there are six types of mutation at codon 12 of K-ras gene) detected by the two methods were counted and added together in order to examine the proportion of GAT or GTT mutations, which were the most commonly detected $(95 \%)$ in pancreatic carcinoma, ${ }^{19}$ because there was a difference in the type of mutant gene detected by the two methods.

\section{Results}

Mutant ras gene was detected in 10 of 14 patients with pancreatic cysts (fig 1). It was detected in high amounts $((2+)$ or more) in six of the 14 cases $(43 \%)$. In cases of pancreatic carcinoma and intraductal papillary neoplasms of the pancreas (IPN), it was detected in high amounts $((2+)$ or more) in 10 of 20 cases $(50 \%)$ and in 9 of 15 cases $(60 \%)$ 
Figure 1 Amount of mutant ras gene according to patient classification. Mutant gene was detected in high amounts $((2+)$ or more) in patients with pancreatic carcinoma (Cancer), intraductal papillary neoplasms of the pancreas (IPN), and pancreatic cysts. In contrast, it was detected in low amounts ( $(1+)$ or less) in patients without these features.
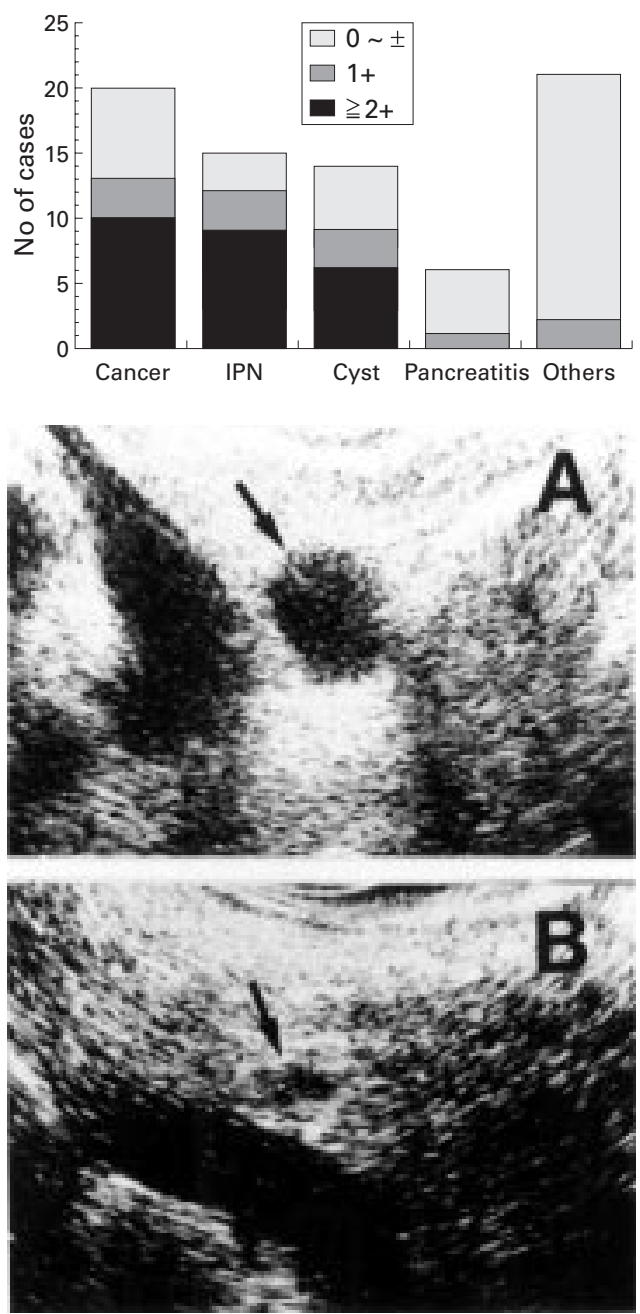

respectively. In contrast, it was detected in low amounts $((1+)$ or less) in all the 27 patients without pancreatic neoplasms, pancreatic cysts, or chronic pancreatitis. This result was consistent with our previous report that the relative amount of K-ras mutant in the pancreatic juice from patients with pancreatic carcinoma and IPN was higher than in that of other patients. ${ }^{9}$ It was concluded that the proportion of mutant K-ras gene in the pancreatic juice from patients with pancreatic cystic lesions was as high as that from patients with pancreatic neoplasms.

With regard to the clinical characteristics of patients with pancreatic cysts, no correlation was found between high amount of ras gene mutant and age, sex, size of cysts, or number of cysts (table 1, fig 2). The average age of the six patients, two men and four women, was 67

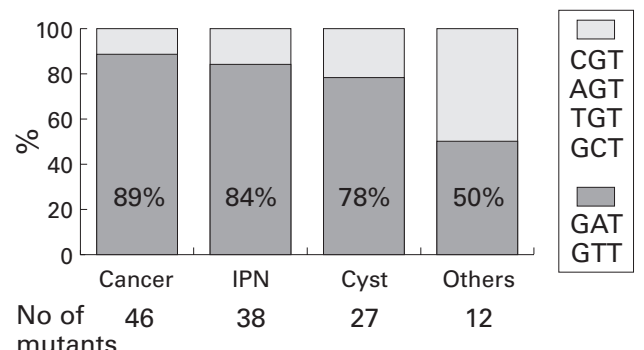

mutants years. The average number of cysts was three and the average maximum diameter was 18 $\mathrm{mm}$.

As for the type of mutated codons, the numbers of codons detected by the two assays were 11 GAT, 10 GTT, three CGT, one TGT, one GCT, and one AGT, in patients with pancreatic cysts. The total number of codons was more than twice the number of patients with the mutation, because different kinds of mutants were detected in the same patient in some cases. The proportion of GAT or GTT was $78 \%$ ( 21 of all the 27 mutations detected by the two different assays) in this study (fig 3). It was $89 \%$ (41 of 46) in patients with pancreatic cancer and $84 \%$ (32 of 38) in those with IPN. It was relatively low (50\%, six of 12) in the other cases. Therefore it was evident that the frequency of GAT or GTT in patients with pancreatic cysts was also high, similar to that in patients with pancreatic neoplasms.

\section{Discussion}

There are many kinds of cysts in the pancreas, more than two thirds being pseudocysts. Pseudocysts are formed when the duct system is ruptured, resulting in leakage of pancreatic juice. Most of them are usually preceded by a history of pancreatitis or trauma, and there has also been a rare case caused by a primary neoplasm of the pancreas. ${ }^{10}$ In this study, pseudocysts were excluded by clinical history and radiological findings, although our series may include cystic lesions associated with mild chronic pancreatitis, which was not diagnosed by imaging modalities. Other common pancreatic cystic lesions are neoplastic, retention, and congenital cysts. ${ }^{11}$ Cystic neoplasms are divided into serous and mucinous adenomas (or adenocarcinomas). Serous cystadenoma is characterised by numerous tiny cysts ranging from 0.1 to $5 \mathrm{~mm}$ with a central scar. ${ }^{22}$ In our study, patient 12 had these characteristics, but mutant ras was not detected. In fact, it was reported that ras gene mutation was absent when serous cystadenoma tissue was analysed. ${ }^{23}$ Mucinous cystadenoma is a cystic pancreatic tumour that occurs almost exclusively in women in the pancreatic body or tail. The tumours are solitary, ranging from 20 to $35 \mathrm{~mm}$ in diameter. ${ }^{11}$ In our study, two patients (nos 3 and 7) with (2+) and (1+) amounts of mutant ras gene may be considered to belong to this category. The other kinds of cyst are solitary or multiple retention and congenital cysts. ${ }^{11}$ Most congenital cysts are associated with von Hippel-Lindau disease or hereditary polycystic kidney disease. ${ }^{11}$ In our series, there were no patients with clinical features of these diseases. Retention cysts occur secondary to obstruction of the pancreatic duct system and most of them are small. ${ }^{11}$ Therefore most of the cystic lesions in patients other than nos 3, 7, and 12 in this study could be retention cysts.

A high rate of mutation of the K-ras gene in the pancreatic juice was detected unexpectedly in most patients with pancreatic cysts as well as in patients with pancreatic carcinoma and IPN. was relatively low in the other cases. Cancer, pancreatic carcinoma; IPN, intraductal papillary neoplasms of the pancreas.
Figure 3 Types of mutant
ras gene according to patient classification. The proportion of codons GAT
or GTT, which were the most commonly detected in analysed according to two methods were counted and added together. The proportion of GAT or GT pancreatic cysts and 
The fact that the frequency of the mutational type of codon was also similar to that of pancreatic neoplasms may suggest that some neoplastic change had already occurred in pancreas with these cystic lesions, although such a lesion was not radiologically detected. The patients in our study showed no clinical or radiological features of pancreatic carcinoma or chronic pancreatitis. However, retention cysts are usually formed in association with chronic pancreatitis or pancreatic cancer. ${ }^{11}$ Small and multiple cysts were found during $15 \%$ of 100 autopsies of patients with pancreatic cancer. ${ }^{24}$ Another study reported that pancreatic cysts co-existed in the pancreas of patients with carcinoma in situ, and that this was the earliest feature of pancreatic cancer. ${ }^{12}{ }^{13}$ These findings may indicate that small cystic lesions in the pancreas reflect the premalignant state of the pancreas.

An alternative possibility is that they represent early lesions of IPN. IPN is another type of pancreatic neoplasm. There is no definite name for this tumour, and IPN, intraductal papilloma, intraductal papillary mucinous tumour, mucin-producing cancer, mucin-hypersecreting neoplasm, and ductectatic cystadenoma or cystadenocarcinoma are all included in this category. ${ }^{25}{ }^{26}$ These neoplasms, although heterogeneous with regard to their epithelial differentiation, form a tumour group that is morphologically and biologically distinct from ductal adenocarcinoma, mucinous cystic tumour, and ductal papillary hyperplasia. In IPN, there is a cystic dilatation of the main pancreatic duct or one of its branches. A widely dilatated ampulla of Vater filled with mucoid material is often observed..$^{11}$ Ras gene mutation has been detected in this type of pancreatic tumour. ${ }^{25}{ }^{27}$ Although typical cases of IPN were excluded by selecting cystic lesions without papillary structure in the cystic wall, without a tendency to grow, without dilatation of the main pancreatic duct, and with normal papilla of Vater, there is still a possibility that these cystic lesions are precursors of IPN before they actually show the characteristic clinical signs.

Of course, it is too early to draw any definite conclusions at this point. The number of patients is too small, and long term follow up of such patients will be required. However, little is known about the risk factors for pancreatic cancer, which makes it particularly difficult to find carcinoma of the pancreas at an early stage. ${ }^{28}$ New radiological techniques such as endoscopic ultrasonography, which is superior to ERCP for the detection of small lesions in the pancreas, have been introduced, ${ }^{29}$ and it has become easier to detect small cysts. Thus we should search carefully for small cystic lesions in the pancreas, and quantify K-ras mutation in the pancreatic juice if the presence of a pancreatic cyst is discovered. If the mutant gene is detected in high amounts, the cyst should be followed up carefully because it may undergo malignant changes.
1 Tada M, Omata M, Kawai S, et al. Detection of ras gene mutations in pancreatic juice and peripheral blood of patients with pancreatic adenocarcinoma. Cancer Res 1993;53:2472-4.

2 Kondo H, Sugano K, Fukayama N, et al. Detection of point mutations in the K-ras oncogene at codon 12 in pure pancreatic juice for diagnosis of pancreatic carcinoma. Cancer 1994;73:1589-94.

3 Trumper LH, Burger B, von Bonin F, et al. Diagnosis of pancreatic adenocarcinoma by polymerase chain reaction from pancreatic secretions. Br F Cancer 1994;70:278-84.

4 Van Laethem JL, Vertongen P, Deviere J, et al. Detection of c-Ki-ras gene codon mutations from pancreatic tumors. Gut 1995;36:781-7.

5 Tada M, Ohashi M, Shiratori Y, et al. Analysis of K-ras gene mutation in hyperplastic duct cells of the pancreas without pancreatic diseases. Gastroenterology 1996;110:227-31.

6 Yanagisawa A, Ohtake K, Ohnishi K, et al. Frequent c-Ki-ras oncogene activation in mucous cell hyperplasia of pancreas suffering from chronic inflammation. Cancer Res 1993;53:953-6.

7 Tada M. Ki-ras utations in chronic pancreatitis: which relevance? Gastroenterology 1996;111:566-7.

8 Kondo H, Sugano K, Fukayama N, et al. Detection of K-ras gene mutations at codon 12 in the pancreatic juice of patients with intraductal papillary mucinous tumors of the patients with intraductal papillary
pancreas. Cancer 1997;79:900-5.

9 Tada M, Teratani T, Komatsu Y, et al. Quantitative analysis of ras gene mutation in pancreatic juice for diagnosis of pancreatic adenocarcinoma. Dig Dis Sci 1998;43:15-20.

10 Hastings PR, Nance FC, Becker WF. Changing patterns in the management of pancreatic pseudocysts. Ann Surg 1975;181:546-51.

11 Solcia E, Capella C, Kloppel G. Tumors of the exocrine pancreas. Atlas of tumor pathology, 3rd series, fascicle 20. Washington, D.C.: Armed Forces Institute of Pathology, 1997.

12 Uehara H, Nakaizumi A, Tatsuta M, et al. Diagnosis of carcinoma in situ of the pancreas by peroral pancreatoscopy and pancreatic cytology. Cancer 1997;79:454-61.

13 Kimura W, Nagai H, Kuroda A, et al. Analysis of small cystic lesions of the pancreas. Int $\mathcal{F}$ Pancreatol 1995;18:197-206.

14 Sambrock J, Fritsch EF, Maniatis T. Molecular cloning: a aboratory manual. Cold Spring Harbor Laboratory, NY: Cold Spring Harbor Laboratory Press, 1989.

15 Tada M, Tateishi K, Yamagata M, et al. Quantitative analysis of ras gene mutation in pancreatic secretions for diagnosis of pancreatic carcinoma: comparison with three different assays. Gastroenterology 1998;114:G2047.

16 Oka T, Matsunaga $\mathrm{H}$, Tokunaga $\mathrm{K}$, et al. A simple method for detecting single base substitutions and its application

7 Levi S, Urbano-Ispizua A, Gill R, et al. Multiple K-ras codon 12 mutations in cholangiocarcinomas demonstrated with a sensitive polymerase chain reaction technique. Cancer Res 1991;51:3497-502.

18 Yamaguchi T, Yun S. Development of new assay for detecting mutant $\mathrm{K}$-ras gene and its application for diagnosis of pancreatic cancer: enriched-PCR/ELMA. Vita 1997;14: pancreatic cancer: en

19 Brunetto MR, Randone A, Ranki M, et al. Quantitative analysis of wild-type and HBeAg minus hepatitis B viruses by a sequence-dependent primer extension assay. $\mathcal{F} \mathrm{Med}$ Virol 1994;43:310-15

20 Hawkins AE, Gilson RJC, Beath SV, et al. Novel application of a point mutation assay: evidence of transmission of hepatitis $\mathrm{B}$ virus with precore mutations and their detection in infants with fulminant hepatitis B. $\mathcal{F}$ Med Virol 1994;44: 13-21.

21 Hruban RH, van Mansfield AD, Offerhaus GJ, et al. K-ras pancreas: a study of 82 carcinomas using a combination of mutant-enriched polymerase chain reaction analysis and allele-specific oligonucleotide hybridization. Am f Pathol 1993;143:545-54.

22 Yamaguchi K, Enjoji M. Cystic neoplasms of the pancreas. Gastroenterology 1987;92:1934-43.

23 Ishiwata T, Nakao A, Nomoto S, et al. Immunochemical and molecular biological studies of serous cystadenoma of the pancreas. Pancreas 1998;16:40-4.

24 Mikal S, Campbell AJ. A carcinoma of the pancreas. Surgery 1950;28:963-9.

25 Sessa F, Solcia E, Capella M, et al. Intraductal papillarymucinous tumors represent a distinct group of pancreatic neoplasms: an investigation of tumour cell differentiation and K-ras, p53 and c-erbB-2 abnormalities in 26 patients. Virchows Arch 1994;425:357-67.

26 Loftus Jr EV, Olivares-Pakzad BA, Batts KP, et al. Intraductal papillary-mucinous tumors of the pancreas: clinicopathological features, outcomes, and nomenclature. Gastroenterology 1996;110:1909-18.

27 Tada M, Omata M, Ohto M. Ras gene mutations in intraductal papillary neoplasms of the pancreas. Cancer intraductal papillar

28 Warshaw AL, Fernandez-del Castillo C. Pancreatic carcinoma. $N$ Engl f Med 1992;326:455-65.

29 Nakaizumi A, Uehara H, Ishii H, et al. Endoscopic ultrasonography in diagnosis and staging of pancreatic cancer. Dig Dis Sci 1995;40:696-700. 